\title{
Protective Effect of Left Ventricular Hypertrophy in Right Coronary Artery Occlusions
}

\author{
Marne de Freitas Gomes, Carlos Antônio Mascia Gottschall
}

\author{
Porto Alegre, RS - Brazil
}

\begin{abstract}
Objective - To test the hypothesis that left ventricular hypertrophy $(\mathrm{LVH})$ reduces the electrocardiographic and functional effects of right coronary artery occlusion.
\end{abstract}

Methods - We analysed 215 patients (166 males and 49 women, age of $58.9 \pm 10.6$ years), with occlusion of the right coronary artery without other associated lesions. There was no significant difference $(p>0.05)$ in age and gender distribution between the 78 patients with LVH (left ventricular mass $>100 \mathrm{~g} / \mathrm{m}^{2}$ ) (Group A) when compared with the 137 patients without $L V H$ (left ventricular mass $<100 \mathrm{~g} / \mathrm{m}^{2}$ ) (Group B).

Results - The electrocardiographic finding of transmural necrosis was more often found in group B patients than in group A patients (56.9\% and $30.8 \%$, respectively; $p<0.05$ ). The left ventricular function parameters of group $A$ were better than those of group $B$ : the ratio end-diastolic pressure/systolic pressure (EDP/SP) (A: 0.108 \pm 0.036 ; $B: 0.121 \pm 0.050 ; p<0.05)$; the end-diastolic volume index $\left(A: 75.9 \pm 31.3 \mathrm{ml} / \mathrm{m}^{2} ; B\right.$ : $\left.88.0 \pm 31.0 \mathrm{ml} / \mathrm{m}^{2} ; p<0.01\right)$; the end-systolic volume index (A: $\left.16.0 \pm 10.0 \mathrm{ml} / \mathrm{m}^{2} ; B: 27.0 \pm 20.0 \mathrm{ml} / \mathrm{m}^{2} ; p<0.001\right)$; the ejection

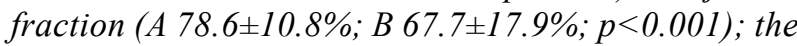
anteroinferior shortening (A: $43.9 \pm 10.3 \% ; B: 35.1 \pm 12.8 \%$; $p<0.001)$. A higher degree of coronary tortuosity was observed in group $A$ than in group B $(78.2 \%$ and $24.1 \%$; $p<0.001)$ and also a more frequent absent or minimal diaphragmatic hypokinetic area (A: 80.8\%; B: 54.0\%; $p<0.05)$.

Conclusion - LVH reduces the effects of myocardial sequela and protects $L V$ function when right coronary occlusion develops.

Keywords: left ventricular hypertrophy, acute myocardial infarction, ischemic cardiopathy

Instituto de Cardiologia do Rio Grande do Sul/Fundação Universitária de Cardiologia - Porto Alegre

Mailing address: Marne de Freitas Gomes - Instituto de Cardiologia do RS - Av. Princesa Isabel, 395 - 90620-001 - Porto Alegre, RS - Brazil
Left ventricular hypertrophy (LVH) is one of the most frequent findings in adult patients with heart disease. Its main cause is high blood pressure (HBP) ${ }^{1-3}$. Considering that arterial hypertension is one of the major risk factors for acute myocardial infarction (AMI ${ }^{4}$ and that the identification of $\mathrm{LVH}$ on the electrocardiogram (ECG) is also considered a risk factor ${ }^{5}$, it is easy to understand the frequent occurrence of AMI in patients with LVH.

In 1949, Harrison and Wood ${ }^{6}$ demonstrated that coronary artery caliber varied directly with heart weight. However, several studies ${ }^{7,8}$ suggest that the increase in the demand for myocardial oxygen due to LVH can exceed the capacity of the coronary arteries to provide oxygen. Coronary arteries become tortuous ${ }^{9}$, even without obstruction, and this leads to ischemia, lesion, infarction, and heart failure ${ }^{10}$. On the other hand, even though in LVH secondary to HBP the coronary flow increases, there is a double increase of the coronary arterial resistance ${ }^{11}$ and decrease in the extraction of lactate. In patients with aortic stenosis, during tachycardia due to atrial stimulation ${ }^{7}$ lactate production can occur suggesting poor myocardial perfusion. However, despite the evidence already documented of the relation between hypertrophy and ischemia, several studies ${ }^{12-17}$ have suggested a certain protective effect of myocardial hypertrophy, restricting the expansion of the infarcted area, when an acute coronary artery occlusion develops.

Studies analyzing separately the hypertensive state and hypertrophy in patients who developed AMI ${ }^{12-17}$ demonstrated that the infarct area expansion and the higher mortality are related to the hypertension and not to the hypertrophy. Pirolo et al ${ }^{12}$, studying 204 autopsied patients, established that the degree of expansion of the AMI was proportional to its size and its transmural characteristic. They also found that the heart weight and the degree of LVH presented a negative correlation with infarction expansion. Boden et al ${ }^{13}$, studying 544 patients, observed that those with LVH and non-Q wave AMI had a smaller enzyme leak than those without LVH and non-Q wave AMI. Behar et al ${ }^{14}$, Ginzton et al ${ }^{15,16}$ and Gomes ${ }^{17}$ reported that after months the 
patients with hypertrophy of the non-infarcted myocardium showed improvement of the rest and exercise ejection fraction (EF), but this did not happen to those who did not develop LVH. Therefore, the post-infarction LVH represented a beneficial myocardial adaptation. The group of Ginzton ${ }^{16}$, studying AMI due to proximal occlusion of the anterior descending coronary artery in dogs, reported that after three and a half months the recovery of the postinfarction EF depends on a correlated increase of the left ventricular mass.

The objective of our study was to clarify possible clinical, electrocardiographic, hemodynamic, and cineangiocardiographic differences between patients with isolated occlusion of the right coronary artery, with or without LVH.

\section{Methods}

This is a retrospective cohort study on 215 patients ( 166 males and 49 females, mean age $58.9 \pm 10.6$ years) with proximal occlusion of the right coronary artery. These patients underwent a first coronary angiocardiographic study in the catheterization and Interventional Cardiology Laboratory in 1992 and 1993. This cohort study is part of broader research on the prognosis of ischemic heart disease, which is being developed. Patients with surgical or percutaneous myocardial revascularization, with obstructive lesions $>50 \%$ in the left coronary tree, and those with associated valvular lesions were excluded from the analysis. All patients underwent a left heart catheterization and coronary angiography more than one month after AMI, usually for risk stratification or due to post-infarction angina. The patients were divided into two groups as follows: group A - patients with LVH (left ventricular mass >100g/ $\mathrm{m}^{2}$ ); group B - patients without LVH (left ventricular mass $<100 \mathrm{~g} / \mathrm{m}^{2}$ ). The left ventricular mass was measured using the ventriculogram.

The ECGs of all patients were analysed and the following findings were considered evidence of LVH: R wave $>26 \mathrm{~mm}$ in V5 or V6; R wave > $20 \mathrm{~mm}$ in DI or DII; R wave $>12 \mathrm{~mm}$ in aVL; $\mathrm{R}$ wave in $\mathrm{V} 5$ or $\mathrm{V} 6+\mathrm{S}$ wave in $\mathrm{V} 1>35 \mathrm{~mm}$. The necrosis was arbitrarily classified into three degrees, according to the possible transmural characteristic of the infarction estimated through Q wave amplitude in aVF lead, as follows: degree 1- Q wave $\leq 0.03 \mathrm{~s}$, amplitude $>20 \%$ of $\mathrm{R}$ wave; degree II $-\mathrm{Q}$ wave $>0.03 \mathrm{~s}$, amplitude $<50 \%$ of $\mathrm{R}$ wave; degree III-Q wave $>0.03 \mathrm{~s}$, amplitude $\geq 50 \%$ of $\mathrm{R}$ wave.

The measurements of the ventricular pressures and the left ventriculogram were performed at the beginning of the examination, prior to coronary angiography, using conventional techniques, and a Besi recorder and the Philips Polydiagnostic DCI for coronary angiography. For the calculation of ventricular volumes, $40 \mathrm{~mL}$ of ionic contrast medium (Meglumine) was injected into the $\mathrm{LV}$ in right anterior oblique view at $35^{\circ}$. The following parameters of $\mathrm{LV}$ were determined in all patients: systolic pressure (SP) and end-diastolic pressure (EDP) in mmHg; end-diastolic and end-systolic volumes (EDV and ESV, respectively) in $\mathrm{mL}$; $\mathrm{EF}$ of LV and anteroinferior shortening (AIS) in \%; left ventricular mass in $\mathrm{g} / \mathrm{m}^{2}$. The measurement of the ventricular volumes was performed through the delimitation of the silhouette of the LV by planimetry and applying the formula of Dodge corrected by Kennedy ${ }^{18}$. For determining the left ventricular mass, the method of Rackley ${ }^{19}$ was used, and a perfect visualization of the cardiac silhouette was considered essential. Nineteen out of the 234 original patients were excluded from the analysis because their delimitations of the cardiac silhouette were not considered precise. In addition to the usual coronary angiographic analysis, coronary tortuosity was evaluated through the tortuosity index (TI) using curvimetry ${ }^{9}$ and was classified into two degrees, as follows: degree I- $\mathrm{TI} \leq 1.1$; degree II $-\mathrm{TI}>1.1$. The repercussion in the LV of the right coronary artery occlusion was evaluated through the area of contractile abnormality obtained by planimetry after remodeling or normalization of the systolic silhouette ${ }^{17}$. According to this area, the abnormalities were classified as follows: absence of or minimum hypokinesia (asynergic area $\leq 1.5 \mathrm{~cm}^{2}$, or $5 \%$ of the diastolic area); moderate or severe hypokinesia (asynergic area $>1.5 \mathrm{~cm}^{2}$ ), with or without akinesia, dyskinesia, or aneurysm.

In regard to the statistical analysis, the database was formed using blind data, and the analysis was performed through the Statgraphics 5.0 program. The quantitative variables were summarized through their means and standard deviation, and the Student's $t$ test was used for comparison of the means in two independent series. The analysis of the qualitative data, expressed by their frequencies and percentages, was performed by comparison of the proportions in the two groups of patients through the chisquare test or, when convenient, through the $\mathrm{Z}$ test for comparison of percentages. The probabilistic values $<5 \%$ $(\mathrm{p}<0.05)$ were considered significant.

\section{Results}

The values of left ventricular mass, which was the criterium for placement of patients in groups A or B, are shown on table I.

The distributions of age and gender of the patients in groups A and B were not statistically different ( $p>0.05$ ), nor was the prior diagnosis of AMI. In group A, the body surface and the incidence of SAH were significantly higher (table II).

The characterization of LVH by means of ECG, according to the criteria proposed, occurred in 26 patients (33.3\%)

\begin{tabular}{|lcc|}
\hline \multicolumn{3}{|c|}{ Table I $-\begin{array}{c}\text { Values of left ventricular mass index (LVMI) } \\
\text { in the patients studied }\end{array}$} \\
\hline Patients & Group A & Group B \\
\hline LVMI $\left(\mathrm{g} / \mathrm{m}^{2}\right)$ & 102 to $331 ; 148.7 \pm 49.2$ & 45 to $98 ; 76.7 \pm 16.6$ \\
\hline Results in: range of variation; mean $\pm \mathrm{sd}$. & \\
\hline
\end{tabular}




\begin{tabular}{|llccc|}
\hline \multicolumn{5}{|c|}{ Table II - Clinical data of the patients studied and statistical } \\
significance of the differences
\end{tabular}

BS- body surface; SAH- systemic arterial hypertension; AMI- acute myocardial infarction; M- mean; sd- standard deviation; NS- not significant.

\begin{tabular}{|c|c|c|c|c|c|c|c|c|}
\hline \multicolumn{9}{|c|}{$\begin{array}{c}\text { Table III - Degrees of necrosis on the electrocardiogram } \\
\text { in the patients studied }\end{array}$} \\
\hline \multirow[t]{2}{*}{ Degrees } & \multirow{2}{*}{$\begin{array}{c}I^{*} \\
\mathrm{n}\end{array}$} & \multirow[b]{2}{*}{$\%$} & \multicolumn{2}{|l|}{ II } & \multirow{2}{*}{$\begin{array}{c}\mathrm{III}^{*} \\
\mathrm{n}\end{array}$} & \multicolumn{3}{|c|}{ Total } \\
\hline & & & $\mathrm{n}$ & $\%$ & & $\%$ & $\mathrm{n}$ & $\%$ \\
\hline Group A & 38 & 56.0 & 16 & 23.5 & 14 & 20.5 & 68 & 100 \\
\hline Group B & 26 & 40.0 & 15 & 23.0 & 24 & 37.0 & 65 & 100 \\
\hline Total & 64 & & 31 & & 38 & & 133 & \\
\hline \multicolumn{9}{|c|}{$\begin{array}{l}{ }^{*} \mathrm{p}<0.05 \text {; degree } \mathrm{I}-\mathrm{Q} \text { wave in aVF } \leq 0.03 \mathrm{~s} \text {, amplitude }>20 \% \text { of the } \mathrm{R} \text { wave; } \\
\text { degree II- } \mathrm{Q} \text { wave in aVF }>0.03 \mathrm{~s} \text {, amplitude }<50 \% \text { of the } \mathrm{R} \text { wave; degree III- Q } \\
\text { wave in aVF }>0.03 \mathrm{~s} \text {, amplitude } \geq 50 \% \text { of the } \mathrm{R} \text { wave. }\end{array}$} \\
\hline
\end{tabular}

\begin{tabular}{|lccl|}
\hline \multicolumn{4}{|c|}{ Table IV-Hemodynamic data and statistical significance of the differences } \\
\hline Measures & Group A & Group B & $\mathrm{p}$ \\
\hline $\mathrm{SP}(\mathrm{mmHg})$ & $151.0 \pm 35.0$ & $143.0 \pm 28.0$ & $\mathrm{NS}$ \\
$\mathrm{EDP}(\mathrm{mmHg})$ & $15.9 \pm 5.3$ & $17.0 \pm 6.8$ & $\mathrm{NS}$ \\
$\mathrm{EDP} / \mathrm{SP}(\%)$ & $10.8 \pm 3.6$ & $12.1 \pm 5.0$ & $<0.05$ \\
EDVI $\left(\mathrm{ml} / \mathrm{m}^{2}\right)$ & $75.9 \pm 31.3$ & $88.0 \pm 31.0$ & $<0.01$ \\
ESVI $\left(\mathrm{ml} / \mathrm{m}^{2}\right)$ & $16.0 \pm 10.0$ & $27.0 \pm 20.0$ & $<0.001$ \\
EF $(\%)$ & $78.6 \pm 10.8$ & $67.7 \pm 17.9$ & $<0.001$ \\
AIS $(\%)$ & $43.9 \pm 10.3$ & $35.1 \pm 12.8$ & $<0.001$ \\
\hline
\end{tabular}

Results expressed in mean \pm sd; SP- systolic pressure; EDP- end-diastolic pressure; EDVI- end-diastolic volume index; ESVI- end-systolic volume index; EF- ejection fraction; AIS- anteroinferior shortening; NS- not significant.

\begin{tabular}{|c|c|c|c|c|c|c|}
\hline \multicolumn{7}{|c|}{ Table V - Coronary tortuosity degrees } \\
\hline \multirow[t]{2}{*}{ Degrees } & \multicolumn{2}{|l|}{$I^{*}$} & \multicolumn{2}{|l|}{ II* } & \multicolumn{2}{|l|}{ Total } \\
\hline & $\mathrm{n}$ & $\%$ & $\mathrm{n}$ & $\%$ & $\mathrm{n}$ & $\%$ \\
\hline Group A & 17 & 21.8 & 61 & 78.2 & 78 & 100 \\
\hline Group B & 104 & 75.9 & 33 & 24.1 & 137 & 100 \\
\hline Total & 121 & & 94 & & 215 & \\
\hline $\begin{array}{l}* \mathrm{p}<0.001 \\
\text { tortuosity }\end{array}$ & . & $\begin{array}{l}\text { ortu } \\
y>1\end{array}$ & cur & $\mathrm{y} \mathrm{u}_{1}$ & ; II- & nary \\
\hline
\end{tabular}

in group $\mathrm{A}$, and in none of the patients in group B. Findings of necrosis through the relation $\mathrm{Q} / \mathrm{R}$ in aVF occurred in 133 patients $(61.8 \%$ of the total) and was more severe in those in group B ( $p<0.05)$, where the occurrences of absence of necrosis or minimum necrosis (degree I) and severe necrosis (degree III) $(\mathrm{p}<0.05)$ were compared. The moderate necrosis (degree II) had a similar incidence in both groups ( $>0.05$ ) (table III).

Table IV shows that ventricular SP and EDP were not statistically different $(p>0.05)$ in groups $A$ and $B$. The different values ( $\mathrm{p}<0.05$ to $<0.001)$ were the following: the relation EDP/SP, the indexes of end-diastolic volume and end-systolic volume, the EF and the anteroinferior shortening of the LV.

In group A, the percentage of patients with normal or decreased coronary tortuosity (degree I) was significantly smaller than the percentage of patients with moderate to severe tortuosity (degree II), but in group B it was the opposite $(\mathrm{p}<0.001)($ table $\mathrm{V})$. There was no significant difference in the presence of collateral flow from the left coronary tree to the right one ( $88.4 \%$ in group $A$ and $83.2 \%$ in group $B ; p>0.05$ ).

Table VI shows that group A had a higher proportion of absence of hypokinetic area or minimum hypokinetic area than group $B(p<0.05)$. The opposite occurred with moderate or severe hypokinesia and dyskinesia $(\mathrm{p}<0.05)$.

Figures 1 and 2 present the relations between left ventricular mass, necrosis, asynergy in the infarcted area, and behavior of left ventricular function.

\section{Discussion}

The presence of LVH in patients with coronary occlusion or AMI is a frequent possibility, not always remembered, because one can lead to the other and SAH can be common to both. The criterium of division into groups according to ventricular mass $\left(>\right.$ or $\left.<100 \mathrm{~g} / \mathrm{m}^{2}\right)$ allowed the separation of two populations with normal distribution and aleatory degrees of left ventricular mass (table I).

Gender distribution and mean age of the patients (table II) were similar ( $>>0.05)$ in the groups with and without LVH. Other studies report older age in patients with $\mathrm{LVH}^{13}$. Diagnosis of SAH occurred in $69.2 \%$ of patients with LVH and in $46.7 \%$ of patients without $\mathrm{LVH}$, confirming that $\mathrm{SAH}$ is prevalent $(\mathrm{p}<0.05)$ in both pathophysiological situations (LVH and AMI).

\begin{tabular}{|c|c|c|c|c|c|c|c|c|}
\hline \multicolumn{9}{|c|}{ Table VI - Degrees of the left ventricle asynergy } \\
\hline Degrees & $\begin{array}{c}\text { Hypokinesia } \\
\text { Abs/Min* } \\
\text { N }\end{array}$ & $\%$ & $\begin{array}{c}\text { Hypokinesia } \\
\text { Mod/Sev* } \\
n\end{array}$ & $\%$ & $\begin{array}{c}\text { Dyskinesia } \\
n\end{array}$ & $\%$ & $\begin{array}{c}\text { Total } \\
\mathrm{n}\end{array}$ & $\%$ \\
\hline Group A & 63 & 80.8 & 14 & 17.9 & 1 & 1.3 & 78 & 100 \\
\hline Group B & 74 & 54.0 & 58 & 42.4 & 5 & 3.6 & 137 & 100 \\
\hline Total & 137 & 72 & 6 & 215 & & & & \\
\hline
\end{tabular}




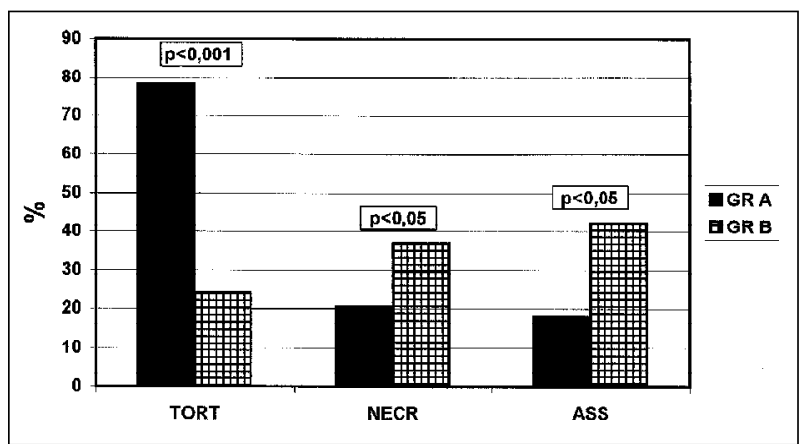

Fig. 1 - In the patients with left ventricular hypertrophy (group A), the greatest left ventricular mass index $\left(149 \pm 49 \mathrm{~g} / \mathrm{m}^{2}\right)$ is associated with a high increase in coronary tortuosity (TORT), half of the transmural necrosis in ECG (NECR) and smaller significant asynergic area (ASS) than in the patients without left ventricular hypertrophy (group B) with smaller left ventricular mass $\left(77 \pm 17 \mathrm{~g} / \mathrm{m}^{2}\right)$.

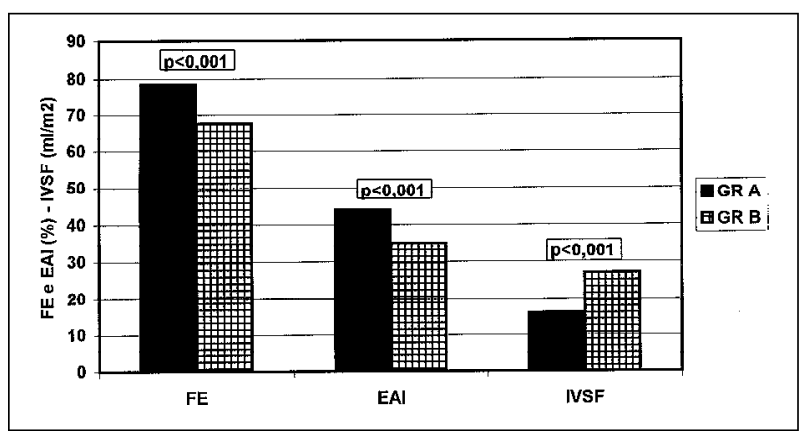

Fig. 2 - In the patients with left ventricular hypertrophy (group A), the greatest left ventricular mass index $\left(149 \pm 49 \mathrm{~g} / \mathrm{m}^{2}\right)$ is associated with a higher ejection fraction (FE), a higher anteroinferior shortening (EAI) and a smaller end-systolic volume index (IVSF) of the left ventricle (VE). All parameters indicate a better contractile function than in the patients without LV hypertrophy (group B), with a smaller left ventricular mass $\left(77 \pm 17 \mathrm{~g} / \mathrm{m}^{2}\right)$.

LVH identified through ECG in patients with AMI has a low prevalence ${ }^{13,14}$, less than $25 \%$, but this has been revealed to be around twice this value in pathological ${ }^{20}$, in ventriculographis ${ }^{19}$ and in echocardiographis ${ }^{21}$ studies. In our study, $36.2 \%$ of the patients had LVH diagnosed by cineventriculography (group A), but ECG identified only 24 patients $(30.7 \%$ of the patients with LVH or $11.1 \%$ of the total number of patients). In the chronic stage, non-Q infarctions are characterized by a greater contractile capacity of the affected area in relation to Q infarctions ${ }^{22}$. The Q-wave size has been used to characterize the significance of the transmural quality ${ }^{23}$ and its relation with $\mathrm{R}$-wave to characterize the size of the infarction ${ }^{24}$. Awan et al ${ }^{25}$ showed a strong correlation between the number of pathological Q-waves and the extension of the asynergy $(r=0.84)$ through ventriculography. The most frequent finding of absence of necrosis or minimal necrosis in patients with LVH (group A) can be an indication of the "protection" promoted by LVH to the myocardium if an infarction happens. As the time gap between the infarction and the angiography was distributed at random between the two groups, it is correct to suppose that the ventricular remodeling of infarcted and non-infarcted areas was not influenced by time.
Although LV SP and EDP were not significantly different $(\mathrm{p}>0.05)$ in the two groups, the EDP/SP ratio, which better expresses LV functionality than does isolated $\mathrm{EDP}^{26}$, was significantly smaller $(\mathrm{p}<0.05)$ in group $\mathrm{A}$, indicating once again a better functional capacity. The smaller values of diastolic volume and mainly of end-systolic volume ${ }^{27}$ in group A than in group B $(\mathrm{p}<0.001)$ also confirm this. This behavior is responsible for an increased EF in group A $(p<0.001)$. It is still a matter of speculation as to what degree this functional behavior can influence a prognosis and clinical behavior.

One can admit that the larger caliber and tortuosity of the coronary arteries represent an expansion of the tree to better nourish the increased ventricular mass ${ }^{6,9,10}$. In our series of patients, this fact is confirmed because coronary tortuosity was significantly more frequent $(\mathrm{p}<0.001)$ in group A than in group B. The smaller regional motion abnormality we observed due to right coronary occlusion in patients with LVH is not emphasized in the literature. The only reference was that hypertrophy is proportional to the degree of necrosis caused by the obstruction ${ }^{15}$. It is worth supposing that the better function in these cases can represent a favorable short- and long-term prognosis.

Several authors ${ }^{12-17}$ postulate that the justification for the beneficial role of $\mathrm{LVH}$ could rest in the larger muscle mass adjacent to the necrotic process, capable of confining the necrosis to the subendocardium and median myocardium. The smallest size of the infarction is demonstrated by the following: smaller rate of enzymatic elevation in patients with AMI and LVH, in comparison to those with AMI without $\mathrm{LVH}^{13}$; greater percentage of patients with $\mathrm{LVH}$ among those with non-Q wave infarction than in the general infarcted population ${ }^{14}$.

The explanation for a tissular structure, which has increased oxygen consumption and decreased coronary reserve, to develop a smaller infarcted area when after a coronary occlusion has been attributed to the development of an effective intra- and intercoronary collateral flow, according to studies carried out in animals ${ }^{28,29}$ and humans ${ }^{30-32}$. Since in our groups the majority of the cases presented collateral flow, this was not a differentiating factor. However, the significant difference can rest not only in the presence but in the degree ${ }^{32}$, in the microvasculature ${ }^{29,30}$, and/or in the moment when the AMI occurs ${ }^{31,32}$, and not more than one month thereafter. It is speculated that the harmful effects attributed to hypertrophy are not directly dependent on its presence, but on the disorders causing the circulatory stress established by variegated stimuli such as neuronal, humoral and metabolic stimuli. These effects can also contribute to facilitating phenomena of cardiac events, among which LVH would be a mere marker ${ }^{33}$. A confirmed mechanism of overload and risk for coronary events is the increase in heart rate, which frequently is part of the same disorder of adrenergic hyperactivity. This hyperactivity is present in the majority of the hypertensive patients and has also been recognized as a factor that might facilitate the 
occurrence of coronary events ${ }^{34}$. On the other hand, pronounced degrees of LVH can determine significant changes in ventricular compliance and contribute to the development of heart failure and arrhythmias ${ }^{35}$.

To conclude, we can say: 1) the absence of a previous clinical diagnosis of AMI is a common finding in right coronary artery occlusion, and it is more frequent in patients with LVH; 2) the localized sequela is significantly smaller in patients with LVH than in those without LVH; 3) patients with LVH show a superior left ventricular functional performance than those without LVH after the development of right coronary occlusion. Therefore, the disorder due to the presence of LVH should be dissociated from the consequence of its determining pathophysiological processes. In the therapeutic control of such situations, LVH might be seen as a marker of continuing circulatory stress, with positive or negative consequences, depending on individual characteristics.

\section{References}

1. Kannel WB - Prevalence and natural history of electrocardiographic left ventricular hypertrophy. Am J Med 1985; 75: 4-18.

2. Savage DD, Garrison RJ, Kannel WB, et al - The spectrum of left ventricular hypertrophy in a general population sample: The Framingham Study. Circulation 1987; 75(suppl): 26-33.

3. Levy D, Anderson KA, Savage DD, Balkus SA, Kannel WB, Castelli WP - Risk of ventricular arrhythmias in left ventricular hypertrophy: The Framingham Heart Study. Arrhythmias and Conduction Disturbances. Am J Cardiol 1987; 60: 560-5.

4. Kannel WB - Role of blood pressure in cardiovascular morbidity and mortality. Prog Cardiovasc Dis 1974; 17: 5-24.

5. Kannel WF, Gordon T, Castelli WP, Margolis JR - Electrocardiographic left ventricular hypertrophy and risk of coronary heart disease. The Framingham Study. Ann Intern Med 1970; 72: 813-21.

6. Harrison CV, Wood P - Hypertensive and ischemic heart disease. A comparative clinical and pathological study. Br Heart J 1949; 11: 205-13.

7. Trenouth RS, Phelps NC, Neill WA - Determinants of left ventricular hypertrophy and oxygen supply in chronic aortic valve disease. Circulation 1976; 53: 644-50.

8. Bache RJ - Effects of hypertrophy on the coronary circulation. Prog Cardiovasc Dis 1988; 31: 403-40.

9. Macruz R, Toriano N, Ariê S, et al - Síndrome da insuficiência coronária não obstrutiva. Tortuosidade das artérias coronárias. Arq Bras Cardiol 1976; 29: 255-62.

10. Carvalho V - Afecções coronárias não obstrutivas. In: Carvalho V, Macruz R (ed) - Cardiopatia Isquêmica. São Paulo: Sarvier, 1989: 255-80.

11. Strauer BE - Left ventricular dynamic energetics and coronary hemodynamics in hypertrophied heart disease. Eur Heart J 1983; 4(suppl A): 137-42.

12. Pirolo JS, Hutchins GM, Moore W - Morphologic studies. Infarct expansion: Pathologic analysis of 204 patients with a single myocardial infarct. J Am Coll Cardiol 1986; 7: 349-54.

13. Boden WE, Kleiger RE, Schechtman KB, et al - Clinical significance and prognostic importance of left ventricular hypertrophy non-Q wave acute myocardial infarction. Am J Cardiol 1988; 62: 1000-4.

14. Behar S, Reicher-Reiss H, Abinader E, et al - Long-term prognosis after acute myocardial infarction in patients with left ventricular hypertrophy on the electrocardiogram. Am J Cardiol 1992; 69: 985-90.

15. Ginzton zle, Conant R, Rodrigues DM, Laks MM - Functional significance of hypertrophy of the noninfarcted myocardium after myocardial infarction in humans. Circulation 1989; 80: 816-22.

16. Ginzton LE, Rodrigues D, Garner D, Laks MM - Functional significance of post-myocardial infarction left ventricular hypertrophy: A beneficial response. Am Heart J 1992; 123: 628-35.

17. Gomes MF - Oclusão da artéria coronária direita em pacientes com hipertrofia ventricular esquerda: análise do padrão hemodinâmico e angiográfico. Tese de Mestrado, IC/FUC, Porto Alegre, RS, 1994.

18. Kennedy JW, Trenholme SE, Kasser IS - Left ventricular volume and mass from single plane cineangiocardiograms: a comparison of anteroposterior and righ anterior oblique methods. Am Heart J 1970; 80: 343-52.

19. Rackley CE, Dodge HT, Coble YD, et al - A method for determining left ventricular mass in man. Circulation 1964; 29: 666-71.

20. Ellis LV, Allison RB, RodriguezFL, et al - Relation of the degree of coronary artery disease and of myocardial infarctions to cardiac hypertrophy and chronic congestive heart failure. N Engl J Med 1962; 266: 525-30.

21. Murray JA, Johnston W, Reid JM - Echocardiographic determination of left ventricular dimensions, volumes and performance. Am J Cardiol 1972; 30: 252-7.

22. Horan LG, Flowers NC, Johnson JC - Significance of the diagnostic Q wave of myocardial infarction. Circulation 1971; 18: 428-36.

23. Williams RA, Cohn PF, Vokonas PS, Young E, Herman MV, Gorlin R - Electrocardiographic, arteriographic and ventriculographic correlations in transmural myocardial infarction. Am J Cardiol 1973; 51: 595-9.

24. Maroko PR, Hillis LD, Muller JE, et al - Favorable effects of hyaluronidase on electrocardiographic evidence of necrosis in patients with acute myocardial infarction. N Engl J Med 1977; 296: 898-903.

25. Awan NA, Miller RR, Vera Z, Janzen DA, Amsterdam EA, Mason DT - Noninvasive assessment of cardiac function and ventricular dyssynergy by precordial Q wave mapping in anterior myocardial infarction. Circulation 1977; 55: 833-8.

26. Gottschall C, Miler V, Rodrigues R - Pressão diastólica final como índice funcional do ventrículo esquerdo. Arq Bras Cardiol 1977; 30: 201-7.

27. White HD, Norris RM, Brown MA, Brandt PW, Whitlock RM, Wild CJ - Left ventricular end-systolic volume as the major determinant of survival after recovery from myocardial infarction. Circulation 1978; 76: 44-51.

28. Cohen MV - The functional value of coronary collaterals in myocardial ischemic and therapeutic approach to enhance collateral flow. Am Heart J 1978; 95: 396-404.

29. Reimer K, Jennings R, Cobb F, et al - Animal models for protecting ischemic myocardium: Results of the NHLBI cooperative study: comparison of unconscious and conscious dog models. Circ Res 1985; 56: 651-65.

30. Zoll PM, Wessler S, Schlesinger MJ - Interarterial coronary anastomoses in the human heart with particular reference to anemia and cardiac anoxia. Circulation 1951; 4: 797-815.

31. Habib GB, Heibig J, Forman AS, et al - Influence of coronary collateral vessels on myocardial infarct size in humans. Circulation 1991; 83: 739-46.

32. Gottschall C - Angioplastia directa e trombólise no infarto agudo do miocárdio. Rev Port Cardiol 1997; 16: 165-74.

33. Frohlich ED, Tarazi RC - Is arterial pressure the sole factor responsible for hypertensive cardiac hypertrophy? Am J Cardiol 1979; 44: 959-63.

34. Gillman MW, Kannel WB, Belanger A, D'Agostino RB - Influence of heart rate on mortality among persons with hypertension: The Framingham Study. Am Heart J 1993; 125: 1148-53.

35. Gottschall C - Diástole normal e anormal. In: Gottschall C-Função Cardíaca: da Normalidade à Insuficiência. São Paulo: Fundo Editorial Byk, 1995; 101-10. 